\title{
公寓装修工程施工技术及方案
}

杨伟

中国水利水电第十一工程局有限公司

DOI:10.32629/ems.v1i1.280

[摘要] 当前,我国装修工程施工存在较大问题,现在建筑业发展越来越快,施工的技术方案尤为重要,装修工程的施工提倡绿色环保,从而 减少装修工程施工对环境带来的污染。本文将围绕公寓装修工程施工展开技术及解决方案。

[关键词] 公寓装修;工程施工;技术方案

\section{1 工程特性}

1.1 施工管理特点

1.1.1 由于公寓装修工程与其它专业交叉点较多, 相关协调和 接口工作也成为该类项目的重点, 使用现金的进度管理手段以及 时应对工序调整。

1.1.2 公寓装修工程很多项目一般处于市区, 施工过程中应严 格管理施工人员及施工车辆的活动范围及路线、材料的场内堆放 等,确保装修施工不会因材料运输影响施工进度。

1.1.3 公寓装修很多项目均需进行深化设计, 为保障装修项目 的质量和进度,必须积极与业主单位沟通及配合,一方面充分发挥 公司在专业设计意图进行深化设计工作, 确保对设计师整体方案 的完美诠释。

1.1.4 公寓装修工程作业面积大,每次进场材料数量都很大,应 在服从业主单位管理的基础上,堆放料区域进行统筹管理,做到堆 场的合理使用。

1.2.施工管理重点

1.2.1 材料供应: 公寓装修施工所用材料种类、规格繁多、部分 材料有业主单位指定采购, 为切实保障施工能够按照预定的工期 进行施工，必须做好现场施工材料的订货、加工工作。

1.2 .2 材料的二次周转及存放保障措施: 制定严密材料二次运
转的工艺要求,保证材料的有序转运及转运过程中的成品保护。为 了保证施工现场的材料供应及现场文明施工，使施工现场做到杂 而不乱,堆放有序, 尽可能的提高场地利用率。以确保材料的二次周 转及存放保障措施。

1.2.3 绿色环保装修:施工中普遍采用绿色环保材料及绿色环 保施工工艺,在施工中严格控制对大气、周边环境的污染、力求尽 可能的减少装修对环境的影响。在进行噪音较大施工时,我们将采 取相应的封闭隔离措施,减少噪音对环境的污染。

\section{2 主要策略}

2.1 在空间上的布署原则一交叉立体施工的考虑

为了贯彻空间占满时间连续、均衡协调有节奏、力所能及留有 余地的原则,保证工程按总体施工进度计划完成,需要采用装修和 安装各工种的立体交叉施工。为了使隐蔽工程正在施工而插人饰 面施工,需要将隐蔽工程分几次验收。

2.2 施工管理主要策略:

2.2 .1 与各专业队建立成品保护制度, 全场挂牌统一成品保护 标志。

2.2.2 以图、表等书面形式向施工班组进行技术交底,并作详细 解释,将设计图、施工方法等内容清楚地传递到施工班组手中,工序 交接以书面形式进行交接记录, 并对工人进行安全文明施工和工
进人其中,进而造成严重污染后果。

3.3.4 大气污染的环境保护措施。在进行沥青混凝土路面的铺 设过程中,由于沥青在各个生产环节均应保持较高温度,所产生的 烟雾扩散至大气中进而造成环境污染。由于沥青拌合过程中容易 产生严重的大气污染,因此应采取必要措施加以控制。在进行沥青 混凝土生产时应严格按照施工技术要求控制温度, 并将沥青拌合 楼设置在居民区下风口位置。在进行沥青加热时要进行封闭式作 业,并且要安装粉尘处理装置。在进行摊铺作业时,要保证摊铺机能 够按照均匀、缓慢、不间断的施工方式进行。进行碾压时要严格控 制速度,铺设完毕后应待其自然冷却至 $50^{\circ} \mathrm{C}$ 时,才可以开放交通。

3.3.5 建筑垃圾的回收利用。市政工程建设主要内容为拆除旧 路面及设备,并展开新工程施工。因此在施工时会产生较多的建筑 垃圾。建设单位应按照垃圾分类原则进行分拣,拆除过程中产生的 各种金属制品废件可进行回收再加工, 实现绿色施工、节能环保。 对于一些不可回收的建筑垃圾, 可选择其中利用价值较高的部分, 在进行路基施工时可将其进行填埋,提升路基坚固度。剩余部分应 进行装袋,并运送至制定区域进行处理。并应注意装车后及时对建
筑垃圾进行覆盖,防止因行驶颠箕造成垃圾散落。

\section{4 结语}

市政道路施工中会较多采用到各种形式的施工策略, 为实现 绿色施工及环境保护的要求, 在开展施工时要注意选择合适的施 工方式,并应加强对环境保护的全程化监控,采取合理措施力求将 环境污染控制在合理范围中。施工过程中较易造成环境污染的因 素为扬尘及垃圾排放, 因此建筑单位要强化针对相关问题的研究, 采取战略性措施制定出可行方案, 促进市政道路绿色施工的顺利 开展。

\section{[参考文献]}

[1]李慧英. 市政道路工程中的绿色施工环境保护措施[J]. 安 徽建筑,2011,18(3):79-80.

[2]张凌.市政道路工程中的绿色施工环境保护措施探讨 [J]. 四川水泥, 2019(4):127-127.

[3]钟南川。市政道路工程中的绿色施工环境保护措施[J]. 中 国标准化, 2017(16): 118 . 
程质量要求岗前培训, 严格执行现场巡查制度和现场技术员全过 程监控重要工序施工的制度。 2.2.3 建立与质量标准挂钩的奖罚制度, 管理人员分层分段管

理。各段施工班组挂牌施工,责任明确分区,奖罚分明,严格执行。

\section{3 工程实施重点、难点分析及解决方案}

3.1 玻璃饰面实施重点、难点分析及解决方案

3.1 .1 重点及难点分析

(1)玻璃装完后松动或不平整

原因分析

(1)裁口内的胶渍、灰砂颗粒、木屑渣等未清除干净。

(2)未铺垫底油灰, 或底油灰厚薄不均、漏涂; 或铺底油灰后, 未

及时安装玻璃,底油灰已结硬失去作用。

(3)玻璃裁制尺寸偏小,影响钉子(或卡子)钉牢。

(4)钉子钉人数量不足; 或钉子没有贴紧玻璃, 出现浮钉, 不起作

用。

(2)外见裁口、里见油灰

原因分析

(1)填抹油灰后,裁油灰时手不稳,出现油灰有宽有窄不均匀。

(2)宽的油灰太满,如果在油灰上再涂刷油漆, 更加重了里见油

灰的弊病,从内部能看见油灰。

(3)窄油灰未填饱满, 既使在油灰上涂刷油漆也达不到要求, 从 外部仍能看见槽口。

(3)油灰棱角不规矩、八字不见角

原因分析

(1)油灰太软或太硬,不易成形或刮平,致使油灰刮理后,表面不 光滑,边沿厚薄不均,交角处未形成八字角。

(2)操作技术欠佳,油灰刀刮放位置不符合要求。

3.1.2 解决方案

(1)玻璃装完后松动或不平整

(1)必须将裁口上的一切杂物事先清扫干净。

(2)裁口内铺垫的底油灰厚薄均匀一致, 不得漏铺。发现底油灰 结硬或冻结必须清除,重新铺垫后,及时将玻璃安装好。

(3)玻璃尺寸按设计裁割, 且保证玻璃每边镶人裁口应不少于 裁口的 $3 / 4$,禁止使用窄小玻璃安装。

(2)外见裁口、里见油灰

(1)刮抹油灰要求具有熟练的操作技术, 并认真按操作规程操 作。

(2)如需涂刷油漆, 刮油灰要比槽口小 $1 \mathrm{~mm}$; 不涂刷油漆的油灰 可不留余量。

(3)油灰棱角不规矩、八字不见角

(1)应根据施工环境温度不同,选择调配软硬适当、无杂质的油 灰。一般冬期油灰要软些,夏天油灰可硬些。

(2)刮油灰时, 油灰刀首先从一个角插人油灰中, 贴紧槽口边用 力均匀、速度平稳地向一个方向刮成斜坡形, 向反方向理顺光滑, 交 接处如不准确,可用油灰刀反复多次修整成八字角为止。

(3)多余油灰应刮除掉; 不足处应补油灰并修至平整光滑。

3.2 油漆工程实施重点、难点分析及解决方案

3.2 .1 重点及难点分析

(1)油漆流挂

指物体的垂直表面上,部分油漆在重力作用下产生流挂。 原因分析
第 1 卷 第 1 期 版本 1.0 2019 年 12 月 8 日 文章类型: 论文 I 刊号( ISSN):2705-0637

(1)油漆太稀, 涂刷太厚或施工环境温度过高, 漆膜干燥太慢等 就会出现流挂。

(2)漆料中含重质颜料过多, 漆膜附着力差, 稀释剂挥发太快或 太慢, 影响漆膜干燥速度; 物体表面不平整, 或有油、水等污物, 造成 漆膜下垂。

(2)开裂或裂纹

指由于面层油漆的扩张与底层不一致而使表面开裂。

原因分析

(1)在软而有弹性的涂层上涂刷稠度大的油漆。

(2)在底层油漆干燥前即涂饰上一层油漆。

(3)干燥剂掺得过多。

(4)漆膜上沾有浆糊或胶水。

(3)漆膜表面起雾

指在罩面漆或磁漆表面上有发白现象, 有时伴有缺乏光泽现 象。

原因分析

(1)在湿冷环境中涂刷油漆。

(2)在有蒸汽的潮湿环境中涂刷油漆。

(3)摩擦刷洗时的水被吸人涂层里。

(4)暴露在含有污染物质的空气中时间过长。

3.2 .2 解决方案

(1)油漆流挂

(1)选择优良的漆料和挥发速度适当的稀释剂。

(2)物体表面处理平整,无油污、水分。

(3)环境温度应符合涂漆标准要求, 涂饰均匀一致, 可避免流挂 下垂现象发生。

(2)开裂或裂纹

(1)正确选择油漆品种。

(2)达到规定的干燥时间后,再涂饰一层油漆。

(3)干燥剂应掺得适量。

(4)漆膜上沾有的浆糊或胶水应立即除去。

(3)漆膜表面起雾

(1)避免在潮湿环境中涂刷油漆。

(2)在干燥环境中涂刷油漆。

(3)在涂刷前应检验被涂物的表面是否干燥, 未干燥不应涂刷 油漆。

(4)除去表面结晶沉淀物, 用亚麻仁油和醋酸的等量混合剂擦 涂表同。

\section{4 公寓装修工程施工技术方案}

4.1 施工技术准备

4.1.1 会同发包方工程师对建筑物的楼地面标高、墙面等进行 全面复核, 以此确定本工程装饰的楼地面标高基准点, 以避免建筑 物实际尺寸与装饰图不符带来的问题。

4.1.2 施工人员认真阅读所有装饰施工图, 并根据复核的现场 实际尺寸作深化翻样, 对图纸上未指明的做法、材料、色泽等问题 立即同发包方和建筑设计师研究商定, 以书面形式增减或变更通 知书,呈发包方或建筑设计师认可后实施。

4.1.3 在工程进人连续施工阶段时, 拟定每周召集一次各工种 施工协调会议,用以解决上一周的问题,制定一周的工作计划,解决 因施工现场与图纸不符等具体问题, 接受发包方和发包方工程师 对施工质量的检查和批评。 
4.1.4 施工测量放样工程

施工人员于施工前,由技术管理人员现场进行技术交底,依据 设计图纸用墨线划出装修物的位置,经技术人员勘查无误后,方可 进行施工,一切尺寸准确性以图纸设计为准。

4.2 玻璃隔断安装工程

施工顺序:

测量定位 $\rightarrow$ 按设计要求做下部结构 $\rightarrow$ 玻璃隔断安装

4.2.1 施工时先按图纸尺寸在墙上弹出垂线, 并在地面及顶棚 上弹出隔断的位置线;

4.2.2 根据已弹出的位置线,按照设计规定的下部做法 (砌砖 板条等)完成下半部,并与两端的砖墙针固;

4.2.3 做上部玻璃隔断时, 先检查砖墙上木砖是否已按规定埋

设。然后按线先立靠墙立筋,并用钉子与墙上木砖钉牢;

4.3 玻璃安装:

4.3.1 安装木托板:一般以钉固法固定在洞口四周的砌体上,宽 度一般应与墙身宽度一致,要求尺寸准确,安装牢固,钉孔间距宜 10 15cm, 木托板与洞口四周的空隙应用石膏淢子或密封胶填满, 应根据设计要求或实际使用情况, 决定是否对木托底部做防腐处 理;

4.3.2 弹出玻璃位置线后,先安装四同一侧的压条,压条宽度尺 寸应根据其与两侧收口线接缝的形式或设计的要求而定, 木压条 一般采用胶粘与钉固相结合的方法进行安装,要求尺寸精确,顺直 光滑,钉孔间距宜 10 15cm,金属条槽一般采用自攻螺丝固定;

4.3.3 安装玻璃前应先铺放一条薄橡胶条,安装玻璃时,玻璃与 安装木托板洞口的上部及两边应留有 $3 \mathrm{~mm}$ 左右的空隙(两边空隙 应相等),以备玻璃的热胀冷缩,大面积玻璃安装必须采用吸盘器;

4.3.4 安装玻璃后必须随即安装四周另一侧的压条, 然后在四 周两侧的空隙注人玻璃胶;

4.3.5 收口线安装一般采用胶粘及钉固法, 其钉孔间距 $10 \sim 15 \mathrm{~cm}$,要求线条流畅,顺直光滑;

4.3.6 玻璃安装完毕后, 必须随即进行另一侧压条的安装, 而且 必须完成安装作业才能下班或交工。完成后应尽快在四周空隙灌 注玻璃胶;

4.3.7 进行木压条、收口线油漆时，应对周围墙身采取保护措 施,避免墙身已完成的批荡或抹灰等工序质量受到污染,同样,在涂 墙身漆时，亦必须对固定玻璃的木压条及收口线等采取保护措施， 避免其产品质量受到影响;

4.3.8 已安装固定完毕的玻璃应挂设或粘上醒目标志, 严禁碰 撞、划伤及化学物质的腐蚀等。

4.4 油漆工程施工
4.4.1 材料要求

(1)涂料:光油、清油脂胶清漆、调合漆、漆片等。

(2)填充料:石膏、地板黄、红土子、黑烟子、大白粉等。

(3)稀释剂:醇酸稀料、松香水、酒精等。

(4)催干剂: " 液体钴干剂 " 等。

4.4 .2 主要机具

主要机具包括:油刷、开刀、牛角板、油画笔、掏子、毛笔、砂纸、 砂布、擦布、淢子板、钢皮刮板、橡皮刮板、小油桶、半截大桶、水桶、 油勺、棉丝、麻丝、竹签、小色碟、高登、脚手扳、安全带、手锤子和小 扫帚等。

4.4.3 作业条件

(1)施工温度宜保持平衡,不得突然变化,且通风良好。湿作业 已完并具备一定的强度,环境比较干燥。一般油漆工程施工时的环 境温度不宜低于 $10^{\circ} \mathrm{C}$, 相对湿度不宜大于 $60 \%$ 。

(2)在室内高于 $3.6 \mathrm{~m}$ 处作业时,应事先搭设好脚手架,并以不 妨碍操作为准。

(3)大面积施工前应事先做样板间,经有关质量部门检查鉴定 合格后方可进行大面积施工。

(4)操作前应认真进行交接检查工作,并对遗留问题进行妥善 处理。

(5)木基层含水率一般不宜大于 $12 \%$ 。

\section{5 结语}

本文主要分析了装修工程施工的相关方面, 结合本文所提出 的相关施工技术以及解决方案, 我们了解到在工程施工的过程中, 通过合理使用绿色施工技术,不仅可以实现建筑的使用功能,而且 还可以最大限度的发挥环境保护效果, 从而更好的减少对环境的 破坏,促进装饰行业的健康快速发展。

\section{[参考文献]}

[1]颜伟铭.分析房屋建筑工程施工技术和现场施工管理方案 [J]. 建材与装饰,2018(35):196-197.

[2]王洪福.现代建筑装饰装修工程施工技术及理念 [J].建材 与装饰,2012(21):56-57.

[3]钱映雪.建筑工程绿色节能施工技术方案探究 [J].建材与 装饰,2018(16):23-24.

[4]王洪福.现代建筑装饰装修工程施工技术及理念[J].建材 与装饰,2012(21):56-57.

[5]张复生.论建筑装饰装修工程的施工理念及质量控制 [J]. 建材与装饰,2013(11):76-78.

[6]王俊啸.建筑装饰装修工程的施工理念及质量控制 [J].科 技创新与应用,2014(27):261-261。 